\title{
Addressing biodiversity loss when international markets of agricultural commodities are oligopolistic
}

\author{
Daniel E. May * \\ Department of Rural Affairs\Environment, Harper Adams University College, Newport, UK
}

Received: 19 March 2012

Revised: 17 April 2012

Accepted: 18 April 2012

\begin{abstract}
Recent evidence shows that international markets of agricultural commodities are oligopolistic. This article uses a theoretical framework to identify the effects of adopting either unilateral (i.e. non-cooperative) or cooperative environmental policies on local biodiversity when countries compete in this market structure. The results reveal that unilateral environmental policies can negatively affect local biodiversity in foreign countries. This suggests that protection of natural habitats can only be achieved by means of international cooperation.
\end{abstract}

Keywords: natural habitats, biodiversity, oligopoly, environmental policies JEL Classification Codes: F18, Q20

\section{Introduction}

Some researchers have found that the most important factors causing natural habitat loss are agricultural expansion induced by international trade and lack of property rights over natural resources (see, for example, Barbier, 2004; and Angelsen and Kaimowitz, 1999). Because natural habitat loss is coupled with loss of biodiversity, this finding suggests that international trade can caused environmental damage. This is because biodiversity provides important economic and environmental benefits such as organic waste disposal, soil formation, biological nitrogen fixation, reservoir of genetic for crop and livestock, biological pest control, plant pollination, and pharmaceuticals (Pimentel et al., 1997). Biodiversity also offers the opportunity to develop alternative economic activities such as ecotourism (Naidoo and Adamowicz, 2005).

The research studying the relationship between international trade and biodiversity has, however, assumed that international markets of agricultural commodities operate in competitive markets (see for instance Polasky et al., 2004; and Smulders et al., 2004).

\footnotetext{
*E-mail: dmay@ harper-adams.ac.uk.

Citation: May, D.E. (2012) Addressing biodiversity loss when international markets of agricultural commodities are oligopolistic, Economics and Business Letters, 1(1), 53-57.
} 
Nonetheless, market power in these markets has been identified by different researchers (see Reimer and Stiegert, 2006; Hueth and Marcoul, 2006; McCorriston, 2002; Ming and Chandramohan, 2002; and Boehlje and Doreing, 2000). According to May (2009), this difference of market structure can strongly affect the relationship between international trade and the environment. As a consequence, environmental policy recommendations provided by works assuming perfect competition could not necessarily be applicable when markets are oligopolistic.

The objective of this article is to show this fact by means of a theoretical analysis. The aim is, in particular, to show that environmental policies adopted to protect local biodiversity by a particular country could negatively affect local biodiversity in foreign countries when they compete in oligopolistic international markets.

The paper is organised as follows. Section 2 introduces the model that is used in the research. Section 3 analyses the effects of both unilateral (i.e. non-cooperative) and cooperative environmental policies on local biodiversity. Finally, Section 4 concludes the paper.

\section{The model}

The model assumes the existence of $\eta$ countries who export a single homogeneous agricultural good to a particular importer country $j$. Let $\Omega$ be the set of exporter countries. Each exporter country $i \in \Omega$ has a single domestic agricultural firm which plays Cournot in the domestic market of country $j$. The demand for the homogeneous agricultural good in the latter is given by $P=\alpha-Q$, where $P$ is the price of the homogeneous good in the domestic market of country $j, \alpha$ represents the size of this market, and $Q$ is the total output demanded by this country. Let $\gamma_{i}$ be the marginal cost faced by the domestic firm of country $i$. Assume, in addition, that the domestic firm of this country produces according to the following function production (Polasky et al., 2004):

$$
q_{i}=\min \left\{N_{i} ; L_{i}\right\}
$$

where $N_{i}$ denotes labour and $L_{i}$ denotes agricultural land used in the production of good $q_{i}$ in country $i$. Farmers, on the other hand, are assumed to maximise the following objective function.

$$
\max _{q_{i}} \pi_{i}=\left(P-\gamma_{i}\right) q_{i}
$$

Using Equations 1 and 2, the solution of the Cournot model under the assumption that the domestic firms of the exporter countries face the same marginal cost (i.e. $\gamma_{i}=\gamma$ for all $i \in \Omega$ ) is:

$$
L_{i}=q_{i}=\frac{\alpha-\gamma}{\eta+1}
$$

On the other hand, if the domestic firms of countries $k \in \Omega-\{i\}$ face the same marginal cost $\gamma$ (i.e. $\gamma_{k}=\gamma$ for all $k \in \Omega-\{i\}$ ) and the marginal cost faced by the domestic firm of country $i$ is $\gamma_{i} \neq \gamma$ (as a consequence of the introduction of a environmental policy in this country), then the Cournot solutions for countries $i$ and $k$ are given by: 


$$
\begin{aligned}
& L_{i}=q_{i}=\frac{\left(\alpha-\gamma_{i}\right) \eta-(\alpha-\gamma)(\eta-1)}{\eta+1} \\
& L_{k}=q_{k}=\frac{2(\alpha-\gamma)-\left(\alpha-\gamma_{i}\right)}{\eta+1}
\end{aligned}
$$

Finally, local biodiversity is introduced by means of the species-area curve (Polaskyet al., 2004). This curve represents a relationship between the size of natural habitat and the number of species it can support. Because land that is converted for agricultural production cannot support native biological diversity, agricultural land expansion negatively affects the number of native species living in natural habitats. This is represented in the model as an inverse relationship between the number of native species and the use of agricultural land. Let $S_{i}$ be the number of native species in country $i$. Using this variable, the species-area curve is defined as:

$$
S_{i}=\theta_{i}\left(L_{i}\right)
$$

where $\theta_{i}\left(L_{i}\right)$ represents the species-area curve as a function of agricultural land. As explained above, the number of native species decreases as agricultural land increases. This implies that $\partial \theta_{i}\left(L_{i}\right) / \partial L_{i}<0$.

\section{Effects of cooperative and non-cooperative environmental policies on local biodiversity}

The existence of market power in international markets of agricultural commodities generates interdependence among competitor exporter countries. This interdependence can negatively affect local biodiversity when environmental policies are adopted unilaterally. To see why, assume that a non-cooperative unilateral environmental policy is adopted by a particular country $i$. Assume in addition that this policy increases the marginal cost of the domestic firm of this country. As a consequence, $\gamma_{k}=\gamma$ for all $k \in$ $\Omega-\{i\}$, and $\gamma_{i}>\gamma$ as a result of the environmental policy adopted in country $i$.

Proposition 1: A non-cooperative environmental policy adopted unilaterally by country $i$ reduces pressure on local biodiversity in this country. However, this policy causes of local biodiversity loss in competitor exporter countries.

Proof: The total effect of the non-cooperative policy adopted by country $i$ on local biodiversity in the same country is given by $d S_{i} / d \gamma_{i}=\left(\partial \theta_{i}\left(L_{i}\right) / \partial L_{i}\right)\left(\partial L_{i} / \partial \gamma_{i}\right)$. From Equation 4 it holds that $\partial L_{i} / \partial \gamma_{i}<0$, and from Equation 6 it holds that $\partial \theta_{i}\left(L_{i}\right) / \partial L_{i}<0$. It must be concluded, therefore, that $d S_{i} / d \gamma_{i}>0$. On the other hand, the total effect of the non-cooperative policy adopted by country $i$ on local biodiversity in a competitor country $k$ is given by $d S_{k} / d \gamma_{i}=\left(\partial \theta_{k}\left(L_{k}\right) / \partial L_{k}\right)\left(\partial L_{k} / \partial \gamma_{i}\right)$. From Equation 5 it is inferred that that $\partial L_{k} / \partial \gamma_{i}>0$, and from Equation 6 it is inferred that $\partial \theta_{k}\left(L_{k}\right) / \partial L_{k}<0$. It must be concluded, therefore, that $d S_{k} / d \gamma_{i}<0$. This completes the proof.

The main implication of this result is that environmental policies adopted unilaterally generate a negative externality on competitor countries as they correct the exogenous shortfall in production of the country with the policy by producing and exporting more. The reason is because a policy adopted by a particular country increases the marginal cost of the domestic firm of this country. This firm adjusts to this policy by reducing 
production and this smaller production, in turn, pushes the price in the importer country up. Competitor countries increase production in response to this higher price. However, the increase in production is achieved by means of agricultural land expansion which negatively affects local biodiversity in these countries.

This finding suggests that countries have to adopt collaborative environmental policies in order to avoid the negative externality on local biodiversity caused by unilateral policies. The following proposition shows that this is indeed possible.

Proposition 2: A cooperative policy adopted simultaneously by all competitor countries benefits their local biodiversity.

Proof: The total effect of the cooperative policy on local biodiversity in an arbitrary country $i$ is given by $d S_{i} / d \gamma=\left(\partial \theta_{i}\left(L_{i}\right) / \partial L_{i}\right)\left(\partial L_{i} / \partial \gamma\right)$. In order to determine the sign of the term $\partial L_{i} / \partial \gamma$ of the right side of this equation, the expression 3 was used. The reason is because this equation assumes that countries face the same marginal cost. This implies that the first derivative of this expression with respect to the marginal cost is associated with the case in which all countries modify their marginal cost simultaneously in the same magnitude. Equation 4, in contrast, cannot be used to prove this proposition because it assumes that only country $i$ modifies marginal cost. Having clarified this point, it is concluded from Equation 3 that $\partial L_{i} / \partial \gamma<0$. On the other hand, from Equation 6 it holds that $\partial \theta_{i}\left(L_{i}\right) / \partial L_{i}<0$. It must be concluded, therefore, that $d S_{i} / d \gamma_{i}>0$, and the proof is complete.

This proposition shows that agricultural land expansion is reduced in all the competitor countries when they adopt a collaborative environmental policy. This is because this policy increases the marginal cost faced by all the domestic firms competing in the importer country. As a consequence, all of them reduce production and this, in turn, reduces pressure on local biodiversity.

\section{Conclusions}

Agricultural land expansion induced by international trade and lack of property rights over natural resources has been identified as an important factor causing loss of local biodiversity. This article explores the main implications of this problem in a world characterised by the existence of oligopolistic international markets of agricultural commodities. The results reveal that in this paradigm, an environmental policy adopted unilaterally by a particular country can negatively affect local biodiversity in competitor countries. This negative externality is not presented in competitive markets because in this case firms are price takers. Consequently, competitor countries do not modify current exports in response to a policy adopted by one of them as output price is not affected by the policy.

This finding was used to conclude that only collaboration among countries can reduce loss of local biodiversity when international markets of agricultural commodities are oligopolistic. According to the results, a beneficial collaborative policy consists of increasing simultaneously the marginal cost faced by firms competing in these markets. This could be achieved, for example, when governments of the countries competing in oligopolistic markets apply simultaneously a tax that increases the marginal cost faced by their domestic firms. The advantage of this collaborative policy is that it does not 
cause negative externalities in competitor countries implying that its application ensures a decrease of habitat destruction at the local and aggregate level.

It is possible that countries' incentives to cooperate depend on how society values the economic and environmental benefits of biodiversity. It would be interesting to investigate how to increase these values with the objective of promoting collaboration across countries that compete in oligopolistic international markets. Willingness to cooperate also depends on governments' political incentives. For example, a government who only cares about gaining political support could not be interested in being involved in international cooperation. The analysis of how to encourage these governments to sign a global cooperative agreement to protect local biodiversity is left for future research.

Acknowledgements. The author wishes to thanks an anonymous reviewer for his/her useful and valuable comments.

\section{References}

Angelsen, A., and Kaimowitz, D. (1998) Economic models of tropical deforestation a review, Center for International Forestry Research CIFOR.

Barbier, E. (2004) Explaining agricultural land expansion and deforestation in developing countries, American Journal of Agricultural Economics, 86(5), 3471353.

Boehlje, M., and O. Doering. (2000) Farm policy in an industrialized agriculture, Journal of Agribusiness, 18(1), 53-60.

Hueth, B., and Marcoul, P. (2006) Information sharing and oligopoly in agricultural markets: the role of the cooperative bargaining association, American Journal of Agricultural Economics, 88, 866-881.

May, D.E. (2009) An international network analysis of the environment, Asia-Pacific Journal of Accounting and Economics, 16(3), 271-284.

McCorriston, S. (2002) Why should imperfect competition matter to agricultural economists?, European Review of Agricultural Economics 29(3), 349-371.

Ming, K., and Chandramohan, D. (2002) Malaysian Palm Oil industry at crossroadsand its future direction, Oil Palm Industry Economic Journal, 2(2), 10-15.

Naidoo, R., and Adamowicz, W.L. (2005) Economic benefits of biodiversity exceed costs of conservation at an African rainforest reserve, Proceedings of the National Academy of Sciences of the United States of America 102(46), 1671216716.

Pimentel, D., Wilson, C., McCullum, C., Huang, R., Dwen, P., Flack, J., Tran, Q., Saltman, T., and Cliff, B. (1997) Economic and environmental benefits of biodiversity, BioScience 47(11), 747-757.

Polasky, S., Costello, C., and McAusland, C. (2004) On trade, land use, and biodiversity, Journal of Environmental Economics and Management, 48, 911925.

Reimer, J.J., and Stiegert, K.W. (2006) Imperfect competition and strategic trade theory: evidence for international food and agricultural markets, Journal of Agricultural \& Food Industrial Organization 4(1), Article 6.

Smulders, S., Soest, D., and Withagen, C. (2004) International trade, species diversity, and habitat conservation, Journal of Environmental Economics and Management, 48, 891-910. 